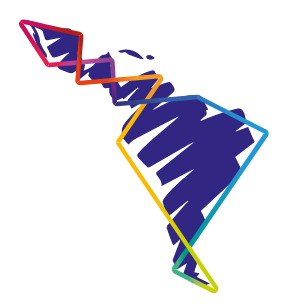

\title{
El principio de soberanía permanente de los pueblos indígenas sobre los recursos en sus territorios
}

\section{The principle of permanent sovereignty of indigenous peoples over resources in their territories}

\author{
María Augusta León Moreta
}

\begin{abstract}
Resumen
La necesidad de los Estados a acceder a recursos naturales en territorios indígenas ha dado lugar a confrontaciones entre diferentes derechos y principios consagrados en el Derecho Internacional Público. El propósito de este artículo es analizar los conflictos entre el principio de soberanía permanente sobre los recursos naturales y el derecho de los pueblos indígenas a la autodeterminación. Por un lado, el principio de soberanía permanente sobre los recursos naturales es un medio para garantizar el acceso de los Estados a los recursos para impulsar su modelo de desarrollo. Por otro lado, el derecho a la autodeterminación permite a los pueblos indígenas acceder a los recursos necesarios para su desarrollo económico, social y cultural. La implementación de proyectos extractivos en territorios indígenas ha tenido como consecuencia la privación del territorio y la limitación del acceso a los recursos, inclusive a aquellos indispensables para su subsistencia. Esto ha socavado significativamente su derecho a determinar libremente su propio modelo de desarrollo, e incluso su supervivencia como pueblos. Ante esta realidad, el artículo plantea la idea de una soberanía inclusiva y no únicamente exclusiva del Estado, a través de la cual los pueblos indígenas aseguren y protejan el acceso a los recursos necesarios para su desarrollo.
\end{abstract}

Palabras clave: Autodeterminación; soberanía; recursos naturales; pueblos indígenas.

\section{Summary}

The need for States to access natural resources in indigenous territories has led to confrontations between different rights and principles established in Public International Law. The purpose of the present article is to analyze the conflicts between the principle of permanent sovereignty

1 Docente investigadora en la Universidad Andina Simón Bolívar, Quito, Ecuador. 
over natural resources and the right of indigenous peoples to self-determination. On the one hand, the principle of permanent sovereignty over natural resources is a means to guarantee a State's access to resources to drive their development model. On the other hand, the right to self-determination allows indigenous peoples to access the resources necessary for their economic, social and cultural development. The implementation of extractive projects in indigenous territories has resulted in the deprivation of their territory as well as the limitation of access to resources, including those indispensable for subsistence. This has significantly undermined their right to freely determine their own development model, and even to warrant their survival as indigenous peoples. Given this reality, the article raises the idea of an inclusive and not only exclusive sovereignty of the State, through which indigenous peoples may secure and protect their access to the necessary resources for their development.

Keywords: Self-determination; Sovereignty; Natural resources; Indigenous peoples.

\section{Introducción}

El modelo de desarrollo económico globalizado requiere que los Estados aseguren el suministro de recursos a sus agentes económicos. En América Latina, especialmente en la región andina, los recursos naturales no renovables como renovables se encuentran muchas veces en territorios ancestrales de pueblos indígenas. La protección a la propiedad sobre los territorios y recursos naturales de estos pueblos ha ido consolidándose a través del Convenio n. ${ }^{\circ} 169$ de la OIT y la Declaración de Naciones Unidas sobre los Derechos de los Pueblos Indígenas. En el ámbito regional, el Sistema Interamericano de Derechos Humanos ha constituido, igualmente, una importante plataforma para la reivindicación y reconocimiento del derecho de propiedad de los pueblos indígenas. Pese a la consolidación de los derechos de estos pueblos en el marco internacional, los Estados se han reservado, con base en el principio de soberanía permanente sobre los recursos naturales, la propiedad sobre aquellos. Esto ha dado lugar a un conflicto multidimensional entre Estados, empresas transnacionales y pueblos indígenas.

En este contexto, el artículo tiene como objetivo explicitar la confrontación entre el principio de soberanía permanente sobre los recursos naturales, medio para asegurar la apropiación de recursos al modelo de desarrollo capitalista, frente al derecho de los pueblos a determinar su propio modelo de desarrollo. Desde este marco de análisis, el artículo respalda la propuesta de dar un giro al alcance y comprensión del principio de soberanía permanente sobre los recursos naturales, entendido como derecho de los Estados a una soberanía de los pueblos indígenas sobre sus recursos que consolide su derecho a la autodeterminación política y económica. 
Para alcanzar este objetivo, el artículo abordará el desarrollo del derecho a la autodeterminación de los pueblos. Posteriormente, explicará el alcance de los elementos que conforman el principio a la soberanía permanente sobre los recursos naturales. Sobre estas bases, se analizará si los pueblos indígenas, como habitantes primigenios, podrían reclamar para sí el principio de soberanía permanente sobre los recursos en sus territorios como condición para el ejercicio de su derecho a la autodeterminación.

\section{El derecho a la autodeterminación de los pueblos}

Las raíces del derecho a la autodeterminación de los pueblos están presentes en los procesos de descolonización, cuando los pueblos de territorios coloniales propugnaron la creación de un nuevo orden que les permitiese expresar su voluntad política y alcanzar sus objetivos económicos, sociales y culturales. En este sentido, el principio a la libre determinación, entendido como principio general de Derecho Internacional (ONU Asamblea General, 1970, párr. 1), guía las relaciones de amistad entre las naciones (ONU, 1945, art. 1), y confiere a los pueblos colonizados la libertad para determinar su estatus político (ONU Asamblea General, 1966a, art. 1; ONU Asamblea General, 1966b, art. 1) y construir la estructura normativa e institucional de un Estado legítimo, reflejo de la expresión de su voluntad política (Anaya, 2004, p. 104; ONU Asamblea General, 1960b, párr. 4; ONU Asamblea General, 970, párr. 15). Fiel a los postulados de la Carta de Naciones Unidas, la Organización de Naciones Unidas colaboró activamente en el establecimiento de las estructuras políticas de los Estados en proceso de descolonización, especialmente en África y Asia.

Simultáneamente, miembros de la comunidad internacional, en reunión de la Asamblea General de Naciones Unidas, plantearon la necesidad de fijar límites al ejercicio de la libertad de los pueblos a constituir un nuevo orden político ante la posibilidad de que minorías pudiesen poner en peligro la soberanía e integridad territorial de los Estados. La Asamblea General, en resolución 1514 (XI) y 2625 (XXV), estableció que el principio de libre determinación no quebrantará total o parcialmente la unidad nacional y la integridad territorial de un Estado, desde la premisa de que el Estado soberano e independiente respete el derecho a la libre determinación y posea un gobierno que represente a todo el pueblo perteneciente al territorio, sin distinción alguna de raza, credo o color (ONU Asamblea General, 1960a, párr. 4 y 6). Consecuentemente, este derecho a la libertad de autodeterminación política podría activarse únicamente cuando los pueblos estén sometidos a dominación colonial o a un régimen racista. Pese a esta evidente aprensión de 
los Estados a las aspiraciones de muchos pueblos presentes dentro de su territorio a determinar libremente su estructura política, social y económica, surgió, en el plano internacional, la discusión sobre si este principio podría ser aplicado a situaciones no coloniales.

Teniendo en cuenta que la raíz primaria del principio de autodeterminación es proteger a los pueblos de la opresión, subyugación, dominación y explotación, actualmente el alcance de la libre determinación de los pueblos, entendida como un principio de derecho internacional, ha sido extendido hacia una moderna interpretación de este principio como un derecho humano (Comité de Derechos Humanos, 1984, párr. 1). ${ }^{2}$ Este derecho habilita a los distintos grupos que conforman una nación a participar activamente en la conformación política dentro de un Estado ya existente (Herdegen, 2005, p. 273). Tanto el art. 1 del Pacto de Derechos Civiles y Políticos como del Pacto de Derechos Económicos, Sociales y Culturales reconoce la libertad de todos los pueblos a construir su desarrollo político, económico, social y cultural (ONU Asamblea General, 1966a, art. 1; 1966b, art. 1). Esto implica el deber de los Estados a promover el autogobierno, a través de instituciones políticas libres, que garanticen la participación popular sin discriminación en la concreción de sus aspiraciones políticas y en la conformación de su desarrollo. En Estados con una fuerte presencia de minorías étnicas en su población, surge el cuestionamiento de que si los pueblos indígenas y otras minorías podrían ser consideradas "pueblos" como titulares del derecho de libre determinación.

Para responder esta pregunta se debe analizar las dos aristas presentes en el Pacto de Derechos Civiles y Políticos. Por un lado, el derecho de autodeterminación del Art. 1 conmina a los Estados a garantiza a los pueblos, desde una perspectiva política, la libertad de construir sus estructuras normativas e institucionales y ejercer el control político sobre las actuaciones del Estado; y desde una perspectiva económica, la libertad de disponer de sus riquezas y recursos para lograr su desarrollo. En este sentido, el ámbito de aplicación personal del derecho de autodeterminación podría ser únicamente extensivo al pueblo de un Estado en su conjunto. Por otro lado, el art. 27 de Pacto de Derechos Civiles y Políticos contiene una declaración general que garantiza a los individuos pertenecientes a minorías étnicas, religiosas o lingüísticas, el derecho a tener su propia vida cultural, a profesar y practicar su propia religión y a emplear su propio idioma, sin que ello implique, de algún modo, el ejercicio del control político (Thornberry, 1989, pp. 877-80). Si bien es cierto

2 En la Observación General n. ${ }^{\circ}$ 12, el Comité de Derechos Humanos subraya la importancia del ejercicio derecho de autodeterminación como "una condición esencial para la eficaz garantía y observancia de los derechos humanos individuales y para la promoción y fortalecimiento de esos derechos". 
ninguno de los pactos provee una definición de minoría, a nivel internacional se ha desarrollado este concepto.

La antigua Corte Permanente de Justicia Internacional, en su Opinión Consultiva de 1930, en relación con las comunidades greco-búlgaras, estableció un concepto de comunidad, el cual es:

Por tradición, ... la "comunidad" es un grupo de personas que viven en un país o localidad determinada, que tiene una raza, la religión, el idioma y las tradiciones de su propia y unidos por esta identidad de raza, religión, idioma y tradiciones en un sentimiento de solidaridad, con el fin de preservar sus tradiciones, manteniendo su forma de culto, lo que garantiza la instrucción y la educación de sus hijos de acuerdo con el espíritu y las tradiciones de su raza y la prestación de asistencia mutua el uno al otro. (Corte Permanente de Justicia Internacional, 1930, p. 21)

Igualmente, el relator especial de la Subcomisión de Prevención de Discriminaciones y Protección a las Minorías, Francesco Capotorti, delineó en su Estudio sobre los derechos de las personas pertenecientes a minorías étnicas, religiosas y lingüísticas, de 1979, un concepto de minorías para ser aplicado al artículo 27 del Pacto de Derechos Civiles y Políticos:

Un grupo numéricamente inferior al resto de la población de un Estado, en una posición no dominante, cuyos miembros - nacionales del Estado - poseen características étnicas, religiosas o lingüísticas que difieren de las del resto de la población y muestran, aunque sea de forma implícita, un sentido de la solidaridad, destinado a preservar su cultura, tradiciones, religión o idioma. (Capotorti, 1979, párr. 568)

Elementos comunes de las definiciones de minoría son: la diferencia numérica en relación con toda la población; la identidad, religión, idioma y tradiciones que difieren del resto de la población, y el deseo de mantener su acervo cultural, religioso y lingüístico. Teniendo en cuenta la condición de vulnerabilidad de las minorías en muchos Estados, el Comité de Derechos Humanos amplía la aplicación del derecho de autodeterminación a "todos los pueblos que no han podido ejercer su derecho a la libre determinación o se han visto privados de la posibilidad de ejercer tal derecho" (Comité de Derechos Humanos, 1984, párr. 6). ${ }^{3}$ A través de la opinión del Comité, el derecho de autodeterminación interna adquiere un carácter universal, al abrir la posibilidad de su incorporación a instrumentos internacionales de derechos humanos y en la normativa constitucional de los Estados (Comité

3 Según el Comité de Derechos Humanos: “... obligaciones concretas a los Estados partes, no sólo en relación con sus propios pueblos sino con todos los pueblos que no han podido ejercer su derecho a la libre determinación o se han visto privados de la posibilidad de ejercer tal derecho...". 
de Derechos Humanos, 1984, párr. 1 y 4; Thornberry, 1989, pp. 877 y 879). La inclusión del derecho de autodeterminación ha sido particularmente importante en instrumentos que protegen los derechos de los pueblos indígenas.

Históricamente, los pueblos indígenas han sufrido la opresión de poderes dominantes tanto durante la colonia como después de la constitución del estado-nación. Debido a que las circunstancias de opresión, marginación y discriminación continúan, el derecho de autodeterminación se ha constituido como una garantía para erradicar situaciones de marginación, opresión y para proteger los derechos humanos de los pueblos indígenas (McCorquodale, 1994, p. 863). Es así como el derecho humano a la libre determinación de los pueblos está íntimamente vinculada con el respeto y fortalecimiento de sus instituciones sociales, económicas, culturales y políticas, dentro de los límites establecidos por la integridad territorial y la soberanía de los Estados a los cuales estos grupos pertenecen (OIT, 1989, art. 1b). Según el art. 4 de la Declaración Naciones Unidas sobre los Derechos de los Pueblos Indígenas, el derecho a la libre determinación de estos tiene una doble dimensión: una política y otra económica (ONU, 2007, art. 4).

En relación con la dimensión política, este derecho garantiza la autonomía o autogobierno, el respeto a sus instituciones tradicionales y la participación de los pueblos indígenas en procesos de decisión ligados a medidas internas o locales de carácter político, administrativo y judicial que afectan el ejercicio de sus derechos (Anaya, 2004, p. 103; ONU, 2007, art. 4). En particular, el derecho de autogobierno tiene una relevancia decisiva en la implementación del derecho a la propiedad comunal de los pueblos indígenas. En efecto, el uso continuo de los territorios y recursos depende de sistemas de control tradicionales colectivos de la tierra que garanticen la supervivencia y desarrollo social y cultural de la comunidad (CIDH, 2002, párr.128; 1997, p. 115). En consonancia, con la dimensión política, la dimensión económica del derecho a libre determinación está vinculada con la decisión de los pueblos a escoger un modelo de desarrollo propio y, para lograrlo, estos están en la libertad de disponer de sus riquezas y recursos naturales (CIDH, 2007, párr. 95; ONU Asamblea General, 2007, art. 3; 1966a, art. 1). En el caso específico de los pueblos indígenas, el derecho a la libre determinación constituye el fundamento para garantizar su efectiva participación en la toma de decisiones sobre la gestión y el control de los recursos naturales localizados en sus territorios. Este reconocimiento del control de los pueblos indígenas sobre sus recursos ha sido interpretado por los Estados nacionales como un riesgo para sus políticas de desarrollo. Por ello, muchos Estados se han reservado, tanto en tratados internacionales como en sus constituciones, la soberanía sobre los recursos dentro de su territorio, con el fin de fomentar su desarrollo basado en su modelo 
económico y político, limitando así, en mayor o en menor medida, el derecho de libre determinación de los pueblos indígenas al uso de sus recursos.

En cuanto a la normativa ecuatoriana interna, el grado de aplicación del derecho de autodeterminación en el derecho interno depende de los procesos constitucionales y políticos desarrollados dentro del Estado (Comité de Derechos Humanos, 1984, art. 1; McCorquodale, 1994, p. 864). En el caso del Ecuador, la Constitución caracteriza al Ecuador como "un Estado constitucional de derechos y justicia, social, democrático, soberano, independiente, unitario, intercultural, plurinacional y laico" (EC, 2008, art. 1). Si bien es cierto, la Constitución reafirma el carácter unitario e indivisible del Estado ecuatoriano (EC, 2008, art. 56), reconoce el principio de plurinacionalidad como el derecho de las personas a identificar su pertenencia tanto geográfica como cultural, el cual, a su vez, permite la convivencia de varias naciones culturales o pueblos étnicamente distintos dentro de un Estado unitario (Corte Constitucional Ecuador, 2014, p. 12). Esta convivencia solo puede ser efectiva en la medida en que se reconozca el derecho de los pueblos indígenas a su autodeterminación interna tanto en sus dimensiones política como económica.

Respecto a la dimensión política, la Constitución ecuatoriana garantiza a los pueblos indígenas el autogobierno en sus territorios (EC, 2008, art. 56), en la medida en que los habilita a ejercer la autoridad (EC, 2008, art. 56, art. 257), aplicar su derecho propio o consuetudinario (EC, 2008, art. 56), administrar justicia y a participar en la construcción política de Estado (EC, 2008, art. 56). La inclusión de la dimensión política en la Constitución ha abierto la participación activa de los pueblos indígenas en la construcción y desarrollo de sus instituciones políticas, administrativas y judiciales. Sin embargo, en la práctica, la implementación del autogobierno es aún conflictiva, especialmente en la aplicación de la justicia indígena. El caso la Cocha ilustra la fuerte injerencia del sistema ordinario de justicia en decisiones dictadas por los sistemas de justicia comunitarios (Corte Constitucional Ecuador, 2014, pp. 1-2). ${ }^{4}$

En este caso, la Corte Constitucional del Ecuador centra su análisis en las diferentes concepciones tanto de la justicia indígena como de la justicia ordinaria al momento de juzgar y sancionar la afectación del protegido bien jurídico vida. Según la Corte, la justicia indígena tiene como fin último reestablecer la armonía entre los miembros de la comunidad, mas no juzgar y sancionar la afectación al bien jurídico vida individualmente (Corte Constitucional Ecuador, 2014, pp. 26 y 8). Por el

4 El 9 de mayo del 2010, en la parroquia Zumbahua, de población indígena kichwa hablante, fue asesinado el señor Marco Antonio Olivo Pallo. Al amparo del artículo 171 de Constitución, las autoridades indígenas de las comunidades de la Cocha y Guangopolo establecieron la culpabilidad de cinco jóvenes de la comunidad de Guangopolo e impusieron las correspondientes sanciones según los usos y tradiciones de las comunidades. 
contrario, la justicia ordinaria, en representación del Estado, busca subsanar tanto el impacto social que una muerte provoca (derecho objetivo) como el derecho subjetivo inherente a cada persona (Corte Constitucional Ecuador, 2014, p. 24).

En función del art. 66 núm. 1 de la Constitución y los tratados de derechos humanos suscritos por el Ecuador, el Estado ecuatoriano tiene la obligación de investigar, juzgar y sancionar todo acto que atente contra la vida sin consideración de la raza, sexo, religión o partencia a una comunidad, pueblo o nacionalidad indígena del sujeto agresor o la persona agredida (Corte Constitucional Ecuador, 2014, pp. 25-26). En este sentido, la Corte Constitucional concluye que los delitos contra la vida son de competencia exclusiva de la justicia ordinaria, por lo tanto, deben ser sancionadas de conformidad del Derecho Penal Ordinario (Corte Constitucional Ecuador, 2014, p. 28). Al restar competencias a la justicia indígena en el conocimiento de afectaciones a la vida, esta decisión de la Corte Constitucional demuestra la visión colonialista y concentradora del Estado que obstaculiza el ejercicio efectivo del derecho constitucional de los pueblos indígenas a administrar justicia.

Instituciones pertenecientes a la Administración Pública del Ecuador también han violado el derecho de autodeterminación de los pueblos indígenas. La Declaración Americana sobre Derechos de los Pueblos Indígenas establece la obligación de los Estados a reconocer, respetar y proteger los sistemas de familia de los pueblos indígenas. El Estado ecuatoriano, al reconocer a la familia en sus diversos tipos (EC, 2008, art. 67), las formas de organización de los pueblos indígenas (EC, 2008, art. 57) y el ejercicio de funciones jurisdiccionales a las autoridades de estos pueblos (EC, 2008, art. 171), abre el camino para el reconocimiento del matrimonio ancestral indígena como parte del ordenamiento jurídico ecuatoriano. En el caso de Manuela Picq y Yaku Sacha, la Dirección Nacional de Registro Civil, Identificación y Cedulación en oficio de octubre del 2017 se negó a inscribir el matrimonio ancestral de ambas personas ciudadanas con el argumento de "... precautelar la seguridad jurídica de la institución del Matrimonio Civil..." (EC Dirección Nacional de Registro Civil, Identificación y Cedulación, 2017). A través de este ejemplo, es posible ilustrar cómo las entidades estatales no terminan de incorporar en su actuación el respeto a los derechos de los pueblos indígenas, tanto garantizados en instrumentos internacionales de derechos humanos como en la propia Constitución.

En cuanto a la dimensión económica, la Constitución del Ecuador garantiza a los pueblos indígenas la imprescriptibilidad de las tierras comunitarias, el uso, usufructo, administración y conservación de los recursos naturales renovables que se hallen en sus tierras ((EC, 2008, art. 57). Sin embargo, como se indicó anteriormente, la libertad de los pueblos indígenas a gestionar y controlar estos 
recursos está limitada por la reserva que realiza el Estado ecuatoriano a su derecho de administrar, regular, controlar y gestionar los recursos naturales no renovables (EC, 2008, art. 313). Esta dicotomía presente en la Constitución y en tratados internacionales de derechos humanos trae una enorme conflictividad ante planes y programas de prospección, explotación y comercialización de recursos no renovables que se encuentren en territorios indígenas.

En conclusión, el derecho a la autodeterminación de los pueblos tiene una doble faceta. Por un lado, este derecho es un principio de derecho internacional que habilita a los pueblos a establecer un nuevo orden jurídico - institucional siempre y cuando aquellos se encuentren bajo un régimen colonialista o racista. Por otro lado, este derecho tiene un carácter de derecho humano que garantiza, dentro de un Estado nacional, la participación de minorías en la construcción de su modelo de desarrollo político, económico y social. En relación con los pueblos indígenas, el derecho a la libre determinación constituye uno de los pilares fundamentales para garantizar ser incluidos en la participación política y el control sobre los recursos naturales necesarios para su desarrollo y supervivencia. Aunque en la práctica, el ejercicio del derecho de autodeterminación tiene todavía muchos retos que afrontar, especialmente en cuanto a la reserva de los Estados sobre la propiedad de los recursos naturales.

\section{El principio de soberanía permanente sobre recursos naturales}

La soberanía permanente sobre los recursos naturales es un principio de derecho internacional que tiene sus orígenes en la lucha de los pueblos colonizados por determinar libremente su estatus político y perseguir su desarrollo económico, social y cultural. Desde el inicio de años cincuenta, este principio ha constituido el fundamento legal para garantizar el acceso de los países descolonizados a los beneficios económicos obtenidos de la extracción de recursos naturales en sus territorios. Esto, a su vez, permitió a los nuevos Estados independientes desconocer acuerdos y contratos firmados por empresas extranjeras con los Estados coloniales y que eran lesivos a los intereses soberanos del nuevo Estado (Daes, 2004, párr. 6).

El principio de soberanía permanente sobre los recursos naturales, como un elemento esencial para concretizar el principio internacional de autodeterminación económica de los Estados, ha sido incorporado en varios instrumentos internacionales. La resolución 1515 (XV) del 15 de diciembre de 1960 fue el primer instrumento en proclamar el respeto al derecho soberano de cada Estado de disponer sobre su riqueza y recursos naturales (ONU Asamblea General, 1960a, párr. 15). Posteriormente, en resolución 1803 (XVII) de 1962, la Asamblea General reconoció el derecho de los pueblos y de las naciones a la soberanía permanente de 
sus recursos naturales (ONU Asamblea General, 1962, párr. 1) y estableció que cualquier violación a este derecho implica una vulneración a los principios de la Carta de las Naciones Unidas, como el desarrollo de la cooperación internacional y la preservación de la paz (ONU Asamblea General, 1962, párr. 7). Este reconocimiento dio lugar a que este principio de los pueblos a disponer, libremente, sobre sus riquezas y recursos alcanzará el estatus de principio general de derecho internacional al ser incorporado en el art. 1 (2) del Pacto de Derechos Civiles y Políticos y el Pacto de Derechos Económicos, Sociales y Culturales. ${ }^{5}$

Con base en estas consideraciones, el principio de soberanía permanente sobre los recursos naturales puede ser definido como el derecho de los pueblos a usar y explotar libremente sus recursos naturales en concordancia con sus objetivos de desarrollo nacional ${ }^{6}$ y el bienestar de su población. Este concepto comprende tres elementos: uno subjetivo, otro objetivo y el límite al ejercicio de este principio.

El elemento subjetivo se refiere a la titularidad de este derecho. La resolución 1803 (XVII) de la Asamblea de Naciones Unidas establece que los sujetos titulares del derecho son los "pueblos y naciones". Sin embargo, el ámbito de aplicación ratione personae puede variar según el área de enfoque del instrumento internacional. Mientras que los tratados en el área del derecho ambiental y el derecho económico internacional evidentemente otorgan a los Estados el libre manejo de sus recursos naturales, con el fin de que establezcan libremente sus estrategias para alcanzar su desarrollo económico; los tratados de derechos humanos reconocen este derecho a los "pueblos". En su origen, el término pueblos estaba vinculado a aquellas poblaciones sujetas a un régimen colonial que impedía el ejercicio de su derecho a la autodeterminación política. Al terminar los procesos de descolonización, los Estados asumieron la titularidad del derecho a la permanente soberanía sobre los recursos naturales existentes en sus territorios, con la condición de que estos garanticen y respeten el derecho de los pueblos de su jurisdicción al acceso a los recursos y riquezas naturales ubicados en sus territorios ancestrales (Schrijver, 1997, pp. 8-9).

El elemento objetivo de este derecho constituye los recursos naturales. Tanto los tratados de derecho internacional como la doctrina del derecho internacional

5 Tanto el art. 47 del Pacto Internacional de Derechos Civiles y Sociales como el art. 25 del Pacto Internacional de Derechos Económicos, Sociales y Culturales señalan: "Ninguna disposición del presente Pacto deberá interpretarse en menoscabo del derecho inherente de todos los pueblos a disfrutar y utilizar plena y libremente sus riquezas y recursos naturales".

6 La Asamblea de Naciones Unidas en el art. 1 (2) de la Declaración sobre el derecho al desarrollo estableció que el derecho humano al desarrollo implica la plena realización del derecho de los pueblos a la autodeterminación, que implica "el ejercicio de su derecho inalienable a la plena soberanía sobre todas sus riquezas y recursos naturales" (ONU Asamblea, 1986). 
no han desarrollado un concepto jurídico sobre recursos naturales. De allí que para efectos del presente análisis, recursos naturales comprenden todos los bienes físicos de la naturaleza, así como su valor intrínseco y económico, y la integridad de los sistemas ecológicos, incluyendo el mar, el aire, la tierra, la flora y la fauna, localizados dentro de la jurisdicción nacional de un Estado. ${ }^{?}$

El tercer elemento pone límites al ejercicio de la soberanía del Estado sobre sus recursos naturales. El límite está dado en función de que los beneficios del uso y la explotación de los recursos naturales deben promover el desarrollo nacional y bienestar de la población (ONU Asamblea General, 1952, párr. 1; 1962, párr. 1.; Schrijver, 1997, p. 286). Esta limitación ha sido recogida principalmente en el Derecho Internacional de los Derechos Humanos, en relación con el acceso de recursos naturales en territorios indígenas. Efectivamente, tratados internacionales de derechos humanos han establecido como límite, al principio de soberanía permanente sobre los recursos naturales, la prohibición de privar a un pueblo de sus propios medios de subsistencia (ONU Asamblea General, 1966a, art. 1; 1966b, art. 1). En el caso Saramaka vs. Surinam, la Corte Interamericana de Derechos Humanos (Corte IDH) reafirma la conexión entre el derecho al territorio con el acceso a los recursos naturales como condición elemental para mantener su estilo de vida y garantizar su supervivencia física, cultural y espiritual (CIDH, 2007, párr. 122).

Teniendo en cuenta las consecuencias negativas de la explotación de recursos naturales en territorios indígenas y el reconocimiento de la libertad de estos pueblos a autodeterminarse, cabe preguntarse, si los pueblos indígenas podrían reivindicar la soberanía sobre los recursos naturales ubicados dentro de sus territorios con el Estado. Esta interrogante será respondida con base en los tres elementos analizados anteriormente.

\section{El principio de soberanía permanente de los pueblos indígenas sobre los recursos en sus territorios como condición para el ejercicio de su autodeterminación}

Con el fin de dar respuesta a la pregunta planteada, es indispensable analizar el alcance de los elementos que componen el principio de soberanía parmente sobre los recursos naturales en relación con los pueblos indígenas.

7 De acuerdo con la resolución 3016 (XXVII) de la Asamblea de Naciones Unidas, los recursos naturales comprendidos en términos del principio a la permanente soberanía sobre los recursos son aquellos localizados en el territorio nacional, el lecho marino y el subsuelo dentro de su jurisdicción nacional, y aguas suprayacentes (ONU Asamblea, 1972, párr. 1; Schrijver, 1997, pp. 16-5). 
Respecto al término "soberanía”, es preciso aclarar que para efectos de la aplicación de este principio a los pueblos indígenas, este no se refiere en ningún caso a la soberanía en plano de las relaciones entre Estados, entendida como la independencia de cada Estado ${ }^{8}$ de ejercer la competencia para desarrollar funciones estatales sobre el territorio y las personas, así como el derecho a ser reconocidos como miembros plenos de la comunidad de Estados (Herdegen, 2005, 183, pp. 216-220; Reports of international arbitral awards, 1928, p. 838). Más bien, la soberanía permanente de los pueblos indígenas a sus recursos se refiere a la facultad de estos pueblos para administrar y controlar, independientemente, sus recursos sobre el fundamento de la posesión ancestral sobre sus territorios y su derecho de autodeterminación (ONU Secretario General, 1955, párr. 19-21). ${ }^{9}$

En este sentido, tratados internacionales, como el Convenio 169 y la Declaración de las Naciones Unidas sobre los derechos de los pueblos indígenas han ratificado el reconocimiento del derecho de los pueblos indígenas a utilizar, administrar, controlar y conservar sus recursos, según sus propias prioridades en lo que atañe al proceso de desarrollo (OIT, 1989, arts. 7, 15; ONU Asamblea General, 2007, art. 26). Esto, a su vez, ha impuesto a los Estados la obligación de respetar, proteger y promover el control, administración y propiedad de los pueblos indígenas sobre sus recursos naturales (Daes, 2004, párr. 40).

Este reconocimiento ha sido ratificado por la Corte Interamericana en su jurisprudencia, al señalar que la titularidad de las tierras de integrantes de los pueblos indígenas y tribales es una condición esencial para garantizar la seguridad, la permanencia del control y uso de los recursos naturales necesarios para mantener su estilo de vida (CIDH, 2007, párr. 122). En este sentido, el elemento de limitación al ejercicio de la soberanía de los Estados, que da paso a una soberanía inclusiva, estaría cumplido.

En concordancia con la normativa y jurisprudencia internacional, cada vez más Estados han reconocido, vía constitucional o jurisprudencial, a los pueblos indígenas como entidades políticas soberanas en el ejercicio del autogobierno dentro de sus comunidades y territorios ancestrales (Corte Suprema de EE. UU., 1832, párr. 559)..$^{10}$

8 En el laudo arbirtral de Max Huber en el caso Islas de Palmas, se define soberanía en las relaciones internacionales como independencia.

9 El Secretario General de Naciones Unidas señaló, en 1955, que un elemento básico y elemental del derecho de autodeterminación es que una nación o un pueblo sean dueños de sus propias riquezas y recursos. [“... the right of self-determination certainly included the simple and elementary principle that a nation or people should be master of its own natural wealth or resources"].

10 En el caso de los Estados Unidos, la Corte Suprema consolidó el alcance de la soberanía política de las tribus indígenas sobre sus territorios. En el caso Worcester vs. Georgia el juez John Marshall confirmó que 
En el caso de Ecuador, la Constitución de Montecristi, al reconocer y garantizar a los pueblos indígenas el desarrollo de sus organización social, el ejercicio de la autoridad, la aplicación de su derecho dentro de sus territorios y tierras comunitarias de posesión ancestral (EC, 2008, arts. 57, 60, 171), otorga indiscutiblemente soberanía a los pueblos indígenas sobre el manejo, control y gestión de sus recursos. Así, este principio es perfectamente aplicable para los pueblos indígenas en razón de las injusticias sufridas por estos pueblos durante la colonización y el despojo de sus tierras, territorios y recursos, lo cual ha dado, como consecuencia, la posterior discriminación, marginación y pobreza dentro de los Estados-nación (ONU Asamblea General, 2007, preámbulo).

En cuanto al elemento objetivo, se plantea la interrogante sobre cuáles recursos naturales los pueblos indígenas tendrían soberanía. Los tratados internacionales de derechos humanos vinculados a los pueblos indígenas realizan una diferencia respecto a la titularidad de los recursos naturales. Por un lado, el art. 15 (1) del Convenio 169 de la OIT establece, de manera general, que los pueblos indígenas tienen derechos sobre los recursos naturales en sus territorios. Por otro lado, la Declaración de las Naciones Unidas sobre los derechos de los pueblos indígenas, además de reconocer el derecho de estos pueblos a los recursos, delimita el alcance de su titularidad, puntualizando que dichos recursos son aquellos que por tradición estos pueblos han poseído, ocupado o utilizado o adquirido (ONU Asamblea General, 2007, arts. 25 y 26). Esta línea ha sido compartida por la Corte Interamericana de Derechos Humanos. En el caso Saramaka vs. Surinam, la Corte señaló que el objeto de protección del art. 21 de la Convención Americana de Derechos Humanos incluye los recursos naturales que estos pueblos han usado tradicionalmente y que no son solo necesarios para la propia supervivencia, sino también son un elemento constitutivo en la construcción de su desarrollo y cosmovisión (CIDH, 2006, párr. 118; 2007, párr. 122). En este contexto, en el contexto internacional se ha consolidado la opinión de que los pueblos indígenas son titulares de aquellos recursos necesarios para su subsistencia y desarrollo, y que, por consiguiente, se encuentran sobre la superficie de sus territorios.

Con estas consideraciones es posible concluir que los pueblos indígenas tienen el derecho a ejercer la soberanía permanente sobre los recursos naturales en sus territorios, con el fin de garantizar su autodeterminación económica y el límite a la potestad del Estado de disponer libremente de estos recursos. Así, la comprensión de una soberanía inclusiva permitiría la consolidación de las estructuras políticas y económicas de las comunidades indígenas.

las naciones indígenas deben ser consideradas como comunidades políticas independientes que conservan, indiscutiblemente, su posesión sobre sus tierras desde tiempos inmemorables. 


\section{Conclusión}

El derecho humano a la autodeterminación garantiza la participación de los distintos grupos de una nación en la concreción de sus aspiraciones políticas y de desarrollo. En el caso de pueblos indígenas, el derecho de autodeterminación asegura el autogobierno y la propiedad sobre sus territorios y recursos. A pesar de que el derecho ha sido introducido en instrumentos internacionales y en las constituciones nacionales como la ecuatoriana, la autodeterminación política y económica de estos pueblos continúa siendo desvirtuada por las prácticas coloniales de las estructuras estatales tradicionales. En el caso específico de la autodeterminación económica, esta se ha visto minada y deslegitimada a través del principio de soberanía permanente de los Estados sobre los recursos naturales.

El principio de soberanía permanente de los Estados sobre los recursos naturales como principio de derecho internacional asegura a los Estados explotar y usar libremente sus recursos naturales en concordancia con sus objetivos de desarrollo. Debido a la importancia estratégica de ciertos recursos, especialmente aquellos localizados en el subsuelo, los Estados no han dudado en salvaguardar, tanto a nivel internacional como nacional, el acceso a estos. El problema radica en que la extracción de este tipo de recursos implica la privación del territorio. Ante ello, este artículo ha tratado de demostrar que la soberanía sobre los recursos puede ser ejercida también por los pueblos indígenas, no como un elemento de separación del Estado, sino como una institución inclusiva que les permita consolidar su desarrollo político y económico, a través del acceso efectivo a sus recursos.

\section{Referencias}

Anaya, J. (2004). Indigenous Peoples in International Law. Nueva York: Oxford University Press.

Capotorti, F. (1979). Study on the rights of persons belonging to ethnic, religious and linguistic minorities. UN Doc E/CN.4/Sub.2/384/Rev.1. Recuperado de https://digitallibrary.un.org/ record/10387

Comité de Derechos Humanos. (1984). Observación General n. ${ }^{\circ}$ 12, Derecho de libre determinación. Recuperado de https://conf-dts1.unog.ch/1\%20SPA/Tradutek/Derechos_hum_Base/ CCPR/00_2_obs_grales_Cte\%20DerHum\%20\%5BCCPR\%5D.html\#GEN12

Corte International de Justicia. (1971). Legal Consequences for States of the continued presence of South Africa in Namibia (South West Africa) Advisory Opinion. Recuperado de https://www. icj-cij.org/files/case-related/53/5597.pdf 
Corte Permanente de Justicia Internacional. (1930). Advisory Opinion in the Greco-Bulgarian "Communities". Recuperado de https://www.icj-cij.org/files/permanent-court-of-international-justice/serie_B/B_17/01_Communautes_greco-bulgares_Avis_consultatif.pdf

Daes, E. (2004). Informe final de la relatora especial sobre la soberanía permanente de los pueblos indígenas sobre sus recursos naturales. U.N. Doc. E/CN.4/Sub 2/2004/30. Recuperado de http://hrlibrary.umn.edu/demo/IndigenousSovereigntyNaturalResources_Daes.pdf

EC. (2008). Constitución de la República del Ecuador. Registro Oficial 449, 20 de octubre.

Herdegen, M. (2005). Derecho internacional público. México: Universidad Autónoma de México.

Informe de Comisión Interamericana de Derechos Humanos de 24 de abril de 1997. Informe sobre la situación de los derechos humanos en Ecuador. Recuperado de http://www.cidh.org/ countryrep/Ecuador-sp/indice.htm

Informe de la Comisión Interamericana de Derechos Humanos de 27 de diciembre de 2002. Caso Mary y Carrie Dann. Recuperado de http://www.cidh.oas.org/Indigenas/EEUU.11.140.htm

McCorquodale, R. (1994). Self-Determination: A Human Rights Approach. The International and Comparative Law Quarterly, 43(4).

Oficio Dirección Nacional de Registro Civil, Identificación y Cedulación del Ecuador de19 de octubre de 2017. Oficio n. ${ }^{\circ}$ DIGERCIC-CGAJ.DPN-2017-0011-O. Recuperado de https:// twitter.com/ecuachaskiecua/status/921411843394023424

OIT. (1989). Convenio 169 Sobre pueblos indígenas y tribales. Autor.

ONU Asamblea General. (1952a). Derecho a explotar libremente las riquezas y recursos naturales. A/RES/626 (VII). Recuperado de https://undocs.org/es/A/RES/626(VII)

ONU Asamblea General. (1952b). Desarrollo económico integrado y acuerdos comerciales. A/ RES/523 (VI). Recuperado de https://undocs.org/es/A/RES/523(VI)

ONU Asamblea General. (1960a). Acción concertada en pro del desarrollo económico de los países económicamente poco desarrollados. A/RES/1515(XV). Recuperado de https://undocs.org/ es/A/RES/1515(XV)

ONU Asamblea General. (1960b). Declaración sobre la concesión de la independencia a los países y pueblos coloniales. A/RES/1514(XV). Recuperado de https://undocs.org/es/A/RES/1514(XV)

ONU Asamblea General. (1962). Soberanía permanente sobre los recursos naturales. A/RES/1803(XVII). Recuperado de https://undocs.org/es/A/RES/1803(XVII)

ONU Asamblea General. (1966 a). Pacto Internacional de Derechos Civiles y Políticos. Autor. 
ONU Asamblea General. (1966 b). Pacto Internacional de Derechos Económicos, Sociales y Culturales. Autor.

ONU Asamblea General. (1970). Declaración relativa a los principios de derecho internacional referentes a las relaciones de amistad y a la cooperación entre los Estados de conformidad con la Carta de las Naciones Unidas. A/RES/2625 (XXV). Recuperado de https://www.dipublico. org/doc/A-RES-2625(XXV).pdf

ONU Asamblea General. (1986). Declaración sobre el derecho al desarrollo. A/RES/41/128. Recuperado de https://undocs.org/es/A/RES/41/128

ONU Asamblea General. (2007). Declaración de las Naciones Unidas sobre los derechos de los pueblos indígenas.

ONU Secretario General de Naciones Unidas. (1955). Draft international covenant on human rights. A/2929. Recuperado de https://www2.ohchr.org/english/issues/opinion/articles1920_iccpr/ docs/A-2929.pdf

ONU. (1945). Carta de Naciones Unidas. Autor.

Reports of International Arbitral Awards de 4 de abril 1928. Island of Palmas Case (Netherlands, USA). Recuperado de http://legal.un.org/riaa/cases/vol_II/829-871.pdf

Schrijver, N. J. (1997). Sovereignty over natural resources: balancing rights and duties in an interdependent world. Cambrige: Cambrige University Press.

Sentencia Corte Constitucional del Ecuador de 30 de julio de 2014. Sentencia n. ${ }^{\circ} 113-14$-SEPCC. Recuperado de http://portal.corteconstitucional.gob.ec/Raiz/2014/113-14-SEP-CC/ REL_SENTENCIA_113-14-SEP-CC.pdf

Sentencia Corte Interamericana de Derechos Humanos de 28 de noviembre de 2007. Caso Pueblo Saramaka vs. Surinam. Recuperado de http://www.corteidh.or.cr/docs/casos/articulos/ seriec_172_esp.pdf

Sentencia de Corte Suprema de Estados Unidos de 18 de marzo de 1832. Samuel A. Worcester Plaintiff in Error v. The State of Georgia, 31 U.S. 515, 6 Pet. 515, 8 L.Ed. 483. Recuperado de https://www.courtlistener.com/opinion/85797/worcester-v-georgia/

Thornberry, P. (1989). Self-Determination, Minorities, Human Rights: A Review of International Instruments. The International and Comparative Law Quarterly, 38(4).

60 \begin{tabular}{l|l} 
Revista Latinoamericana de Derechos Humanos \\
Volumen 30 (2), II Semestre 2019 \\
ISSN: 1659-4304 • EISSN: 2215-4221
\end{tabular} 